\title{
"No TODO FUE HISPÁNICO EN LA CASA DE LOS LARRETA". INTERVENCIÓN ARQUEOLÓGICA EN EL JARDÍN DEL MUSEO LARRETA
}

\author{
Ricardo Orsini y Horacio Padula*
}

\begin{abstract}
Resumen
Durante un relevamiento realizado en el jardín del Museo Larreta, con motivo del hundimiento de tierra en dos sectores del mismo, se pudo constatar en ambos, la presencia de estructuras sanitarias. No obstante, solo una de ellas fue reutilizada como pozo de descarga, lo cual motivó su intervención arqueológica. Los resultados de la misma determinaron que se trataba de un antiguo pozo de desechos cloacales, y que tras su inutilización fue aprovechado para descartar materiales diversos durante las primeras décadas del siglo XX.
\end{abstract}

Palabras clave: Estructura sanitaria, reutilización, pozo de descarga y reformas edilicias

\begin{abstract}
During a survey carried out in the garden of the Museo Larreta, on the occasion of the sinking of land in two sectors of the same, it was possible to see in both the presence of sanitary structures. However, only one of them was reused as a discharge well, which motivated its archaeological intervention. The results of the same determined that it was an old sewage pit, and that after its inutilization it was used to discard diverse materials during the first decades of the twentieth century.
\end{abstract}

Keywords: Sanitary structure, reuse, discharge well and building reforms

\section{Intervención y diagnóstico}

El 9 de septiembre de 2015, personal del equipo de arqueología de la actual Gerencia Operativa de Patrimonio, dependiente de la Dirección General de Patrimonio, Museos y Casco Histórico - órgano de aplicación de la Ley 25.743 de protección del patrimonio arqueológico y paleontológico en el ámbito de la Ciudad Autónoma de Buenos Aires- llevó a cabo un relevamiento arqueológico en dos sectores del jardín del Museo Larreta (Juramento 2291). Las tareas se desarrollaron a partir de una denuncia de las autoridades del Museo, quienes ante los hundimientos de tierra producidos en el jardín (y la visualización de hiladas de ladrillo en dichos hundimientos), supusieron la posible presencia de algún tipo de estructura arqueológica.

El diagnóstico inicial constató la presencia de dos estructuras subterráneas. La primera de las mismas ( $\mathrm{N}^{\mathrm{o}} 1$ - Sector $\mathrm{M}$ de acuerdo a una nomenclatura de la propia Dirección del Museo, cercano a la calle $\mathrm{Cuba}$ ) fue interpretada como un pozo sanitario, muy frecuentes en construcciones del siglo XIX. Presentaba una bovedilla de ladrillos, con una abertura de $0,30 \mathrm{~m}$ de diámetro, y tenía $1 \mathrm{~m}$ de

\footnotetext{
* Gerencia Operativa de Patrimonio, Dirección General de Patrimonio, Museos y Casco Histórico. G.C.B.A. orsiniricardo@yahoo.com.ar; horaciopadula@hotmail.com
} 
profundidad hasta el relleno. Por encima de la bovedilla se apreciaba el paso de un caño sanitario de más reciente cronología, El pozo también estaba invadido por raíces que provenían de un árbol de palta (Persea americana) situado a pocos metros.

En el pozo $\mathrm{N}^{\mathrm{o}} 2$, por su parte (próximo a la parte trasera del museo, ubicado en el sector $\mathrm{N}$ del jardín, y lindando con las gradas de un teatro abierto allí presente), se apreciaba una abertura de 0,70 $\mathrm{m}$ de diámetro máximo y 1,20 m de profundidad. En el interior de la estructura se identificó una acumulación de fragmentos de ladrillos, posiblemente producto del derrumbe de la bovedilla del pozo. Las raíces que se visualizaron asociadas espacialmente a estos ladrillos pudieron haber contribuido al desmoronamiento.

\section{Relevancia histórica}

El lugar donde actualmente se encuentra el Museo Larreta, se ubica en tierras que de acuerdo a lo que puede apreciarse en el plano de tierras de Belgrano levantado por el Ing. Descalzi en 1855, pertenecieron a la familia Rosas, hasta que en 1857 fueron declaradas propiedad municipal (Allende, Andrés 1958 "Los orígenes del pueblo de Belgrano"), para luego pasar a ser propiedad de Vanega hasta formar parte de la chacra de quien fuera juez de paz, y Presidente de la comisión Municipal entre 1861 y 1863, Laureano Oliver. Años después don Francisco Chas adquirió parte de la propiedad, y encomendó la construcción de una casa de veraneo a su yerno Ernesto Bunge. En 1892, fue adquirida por Mercedes Castellanos de Anchorena, quien la entregó como regalo de bodas a su hija Josefina cuando ésta se casó con Enrique Larreta en 1903. En 1916, el matrimonio le encomendó al arquitecto Martín Noel las modificaciones necesarias para que la casona sirviera como residencia permanente, resultando el edificio actual de estilo neo colonial.

La importancia de este sitio radica en que geográficamente se ubica en el área fundacional de lo que fuera el pueblo de Belgrano, por lo que la información que pudiera recuperarse arqueológicamente es de relevancia no solo en relación con el conocimiento de los usos y costumbres domésticos de las familias que habitaron en este lugar, sino además para abordar la historia del barrio en general.

\section{Intervención arqueológica}

La primera de las intervenciones se efectuó en el Pozo $\mathrm{N}^{\circ}$, un pozo ciego de sección circular. El mismo se encontraba estructurado por 30 hiladas de ladrillo, y contaba con un diámetro máximo de $1 \mathrm{~m}$. La bovedilla se encontró dañada, posiblemente debido al paso de un caño de desagüe que la atraviesa a pocos centímetros de la superficie.

Los ladrillos que componen el perímetro del pozo se ubican de manera frontal en dirección al centro del mismo y se encuentran fraccionados intencionalmente.

La excavación, que se extendió por más de cinco meses, se efectuó hasta una profundidad de cinco metros, desistiendo de continuar debido a las posibilidades de derrumbe. Las 10 hiladas inferiores de ladrillos ya demostraban signos de colapso ubicándose las mismas muy por fuera de su ubicación originaria (Figura 1).

El interior del pozo estaba relleno de tierra, incluyendo gran cantidad de materiales de construcción, entre los que se encontraron fragmentos de escombros, de contrapisos, de ladrillos, y de revoques de paredes, vidrios planos, clavos de cabeza redonda y fragmentos de caños.

Entre otros objetos fueron rescatados fragmentos de vajilla de loza, botellas de vidrio de bebidas, frascos de perfume, engranajes metálicos de función aún desconocida, flejes de barriles, sanitarios cerámicos, dos manijas metálicas de balde de pozo, restos de un posible cantero de origen oriental, material óseo posiblemente asociado a la alimentación de la época de su descarte, restos malacológicos, y rocas pertenecientes a la ingresión belgranense. 


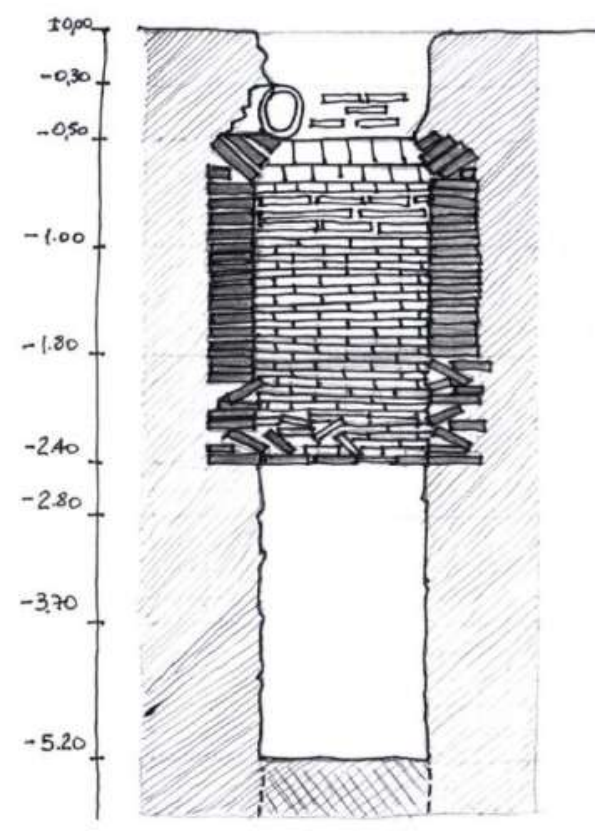

Figura 1: Corte del Pozo $\mathrm{N}^{\circ} 1$ en el que se pueden apreciar los daños sufridos por la estructura en su parte superior, en particular por el paso de un caño de desagüe más moderno, y en las hiladas inferiores, por la acción de raíces de árboles cercanos (Dibujo Arq. Mónica Sanjurjo y Arq. Graciela Aguilar)

Las variaciones estratigráficas fueron establecidas artificialmente, de acuerdo a la irrupción de diferentes tipos de concentración de materiales que fueron descartados en la estructura sanitaria.

Como se mencionó, el descarte total de material en el Pozo 1 se encuentra conformado principalmente por material de construcción, en el que sobresalen restos de escombros y ladrillos (no contabilizados); y por otro lado, un alto porcentaje de fragmentos de vidrio, en particular del tipo plano, propio de ventanas, que representa un $89,4 \%$ sobre el total hallado de este tipo de material. En menor proporción, casi un $7 \%$, se recuperaron fragmentos de botellas y frascos, cerca de un $3 \%$ de vidrios grabados, posiblemente de aberturas tales como catedral, lustre azul, acanalado, y floreal borravino (Figura 2).

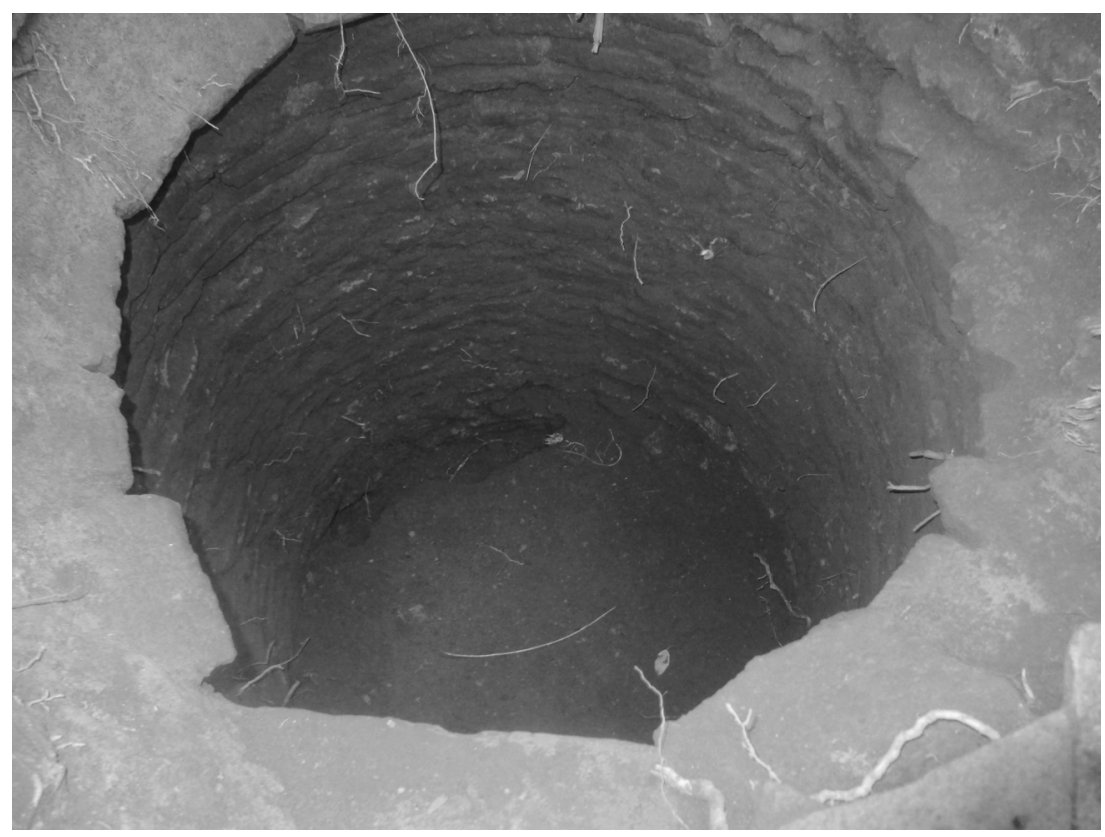

Figura 2: Estructura sanitaria (Pozo 1) durante el proceso de remoción de tierra 
Nivel 1: Ubicado desde el punto 0, coincidente con la línea de superficie, hasta los 0,50 m. En este estrato no se aprecian restos materiales más allá de la presencia de un caño de desagüe que atraviesa la boca del pozo y fragmentos de ladrillos producto de la destrucción del brocal.

Nivel 2: Desde los $0,51 \mathrm{~m}$ asociado a la boca del brocal del pozo hasta $1 \mathrm{~m}$ de profundidad, abarcando las primeras siete hiladas de ladrillos de la estructura sanitaria. El registro material predominante se encuentra conformado por fragmentos de macetas de terracota, y en menor medida, de baldosas francesas y ladrillos provenientes de la boca del pozo, ubicados allí tras su destrucción a causa del paso de un caño. También se recuperaron clavos con alto estado de oxidación, y fragmentos de vidrio (frascos de perfume y lamparita de luz).

Nivel 3: A partir de 1,01 hasta 1,80 m, correspondiente a las hiladas de ladrillos 8 a 20 . El material recuperado que predomina en este nivel, se encuentra conformado por ladrillos fragmentados muy rodados, y con menor representación, restos de macetas de terracota, fragmentos de vidrio plano y de lozas, y clavos con alta oxidación.

Nivel 4: Desde 1,81 hasta 2,40 m, relacionado con la hilada 30 de ladrillos, la última de la estructura. Este nivel denota también la presencia de fragmentos de ladrillos, aunque sin mayor presencia de otro tipo de material en relación con el anterior.

Nivel 5: Entre los 2,41 y los 2,80 m de profundidad, se aprecia la presencia de fragmentos de un posible cantero con motivos griegos y orientales. En asociación con el mismo, se observa una importante representación de restos óseos vacunos y ovinos, coquinas correspondientes al belgranense, asociadas a malacofauna cuyo principal representante es el pelecípodo Erodona mactroides, fragmentos de pisos y contrapisos rodillados de cemento, dos botellas de vino, la base de frasco de leche de magnesia, una escarpia metálica, y menor presencia de ladrillos fraccionados.

Nivel 6: Desde los 2,81 hasta los 3,70 m. Representado por una gran cantidad de fragmentos de pisos y contrapisos rodillados de cemento. En menor proporción, se recuperaron fragmentos metálicos con alta oxidación, fragmentos de caño de plomo, un plato metálico, muñecos de tosca, y molares de vacuno.

Nivel 7: Entre los 3,71 hasta los $5 \mathrm{~m}$. Este nivel se ve representado por una alta presencia de fragmentos de vidrio plano y, en menor proporción respecto al nivel anterior, de material de construcción. También son relevantes los fragmentos de loza, y se destaca la presencia de objetos de uso sanitario como un inodoro de base redonda y un mingitorio.

\section{Registro material y Cronología}

Cuando se emprende la tarea de asignar cronologías en los materiales hallados, se debe resaltar que las mismas responden a los momentos en que los objetos fueron manufacturados, lo cual puede marcar un sesgo temporal con respecto a los instantes de su descarte. A continuación se mencionarán algunos de los objetos que fueron diagnosticados, y que en conjunto pueden brindar una estimación cronológica de las secuencias de descarte involucradas, al menos hasta donde se decidió intervenir la estructura.

\section{Material de construcción}

Entre los restos hallados, pueden apreciarse ladrillos de dimensiones más frecuentes en construcciones propias de la segunda mitad del siglo XIX, (26 cm de largo x $15 \mathrm{~cm}$ de ancho x $5 \mathrm{~cm}$ de espesor) (Schávelzon, 1989). Además, se distinguieron baldosas de $20 \times 20 \mathrm{~cm}$, de tradición francesa, cuyas dimensiones tuvieron en nuestro país una notable difusión a partir de 1852 (Schávelzon, 1991).

Por otro lado, fue hallado un inodoro de forma redonda, con la inscripción grabada "RC J\&M", el cual se estima pueda corresponder a las primeras décadas del siglo XX. El uso de este tipo de 
sanitarios, tuvo su génesis en la ciudad de Buenos Aires a partir de 1871, producto de los desbastadores efectos de la fiebre amarilla. En medio de las críticas condiciones sanitarias de la metrópoli, comenzaron a aplicarse nuevas normativas municipales en materia de políticas y obras de salubridad. Así fue como para 1872 se encuentran los primeros documentos sobre la instalación de inodoros en Buenos Aires. En principio el uso de inodoros estaba circunscripto a residencias suntuosas, y recién a partir de 1887 se tornó obligatoria su instalación en las casas de inquilinato, conventillos, fondas y bodegones que se habilitaran a partir de esa fecha (Prignano 2007).

Los clavos con cabeza redonda se difundieron a partir de las últimas décadas del siglo XIX. Desde lo arqueológico, los registros más tempranos con abundancia de este tipo de material se dieron durante las excavaciones en el Caserón de Rosas, y asociados a las reformas del Colegio Naval de 1892 y 1899 (Schávelzon, 1991). En el Pozo N 1, los ejemplares de cabeza redonda sobresalen cuantitativamente por sobre aquellos de cabeza cuadrada, lo cual nos permite estimar una cronología más precisa.

Uno de los materiales con mayor representación es el vidrio plano de 1,8 mm, muy frecuente en contextos de 1850 a 1900 (Schávelzon, 1991), y aquel con texturas en una de sus caras, presente en nuestro país también durante las últimas décadas del siglo XIX.

\section{Objetos de uso doméstico}

Entre los objetos de uso doméstico, se destacan recipientes de loza con decoraciones impresas propios de la segunda parte del siglo XIX y primeras décadas del siglo XX, y restos de lo que podría ser un cantero cerámico de aproximadamente un metro de diámetro, el cual ofrece un sincretismo entre motivos figurativos orientales en el cuerpo de la estructura, sobresaliendo perros de Foo, aves y plantas por un lado, y trazos geométricos en todo su contorno cercano a la boca de la misma, asociados a la tradición griega entre el 900 y el 700 AC (Período geométrico). Todo el conjunto combinado en coloraciones amarillo -verdosas. Su cronología puede estimarse entre fines del 1800 y principios del siglo XX (Figura 3).
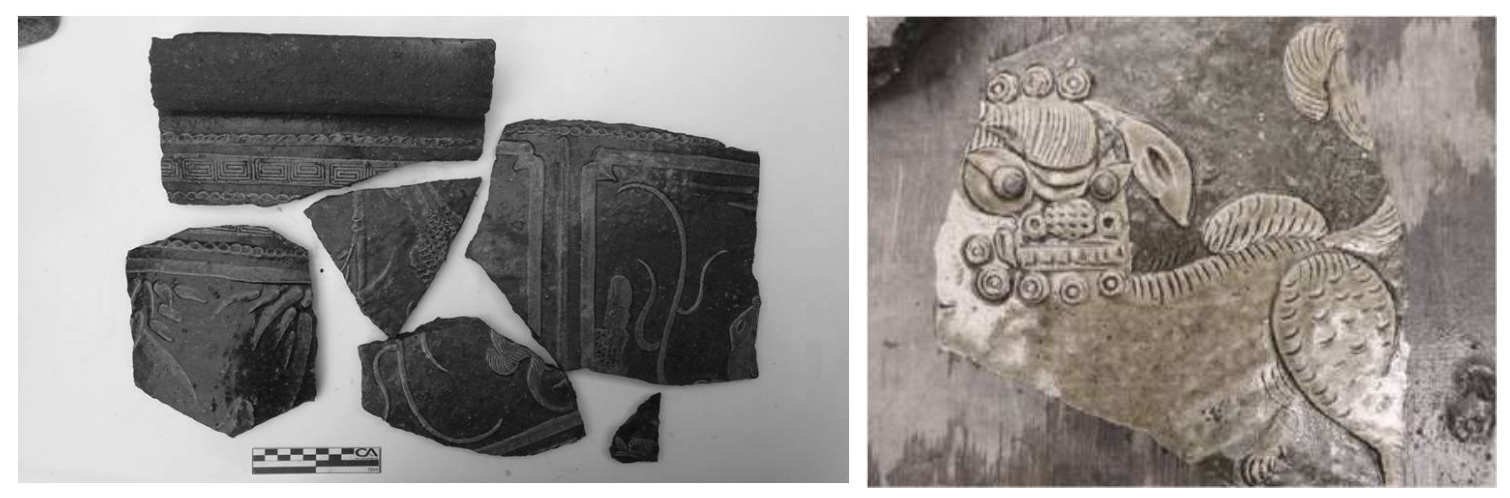

Figura 3: Posible cantero o macetón con motivos orientales y guardas griegas

Entre las botellas sobresalen aquellas de cuello largo y delgado, sin marcas de soplado y moldeado, las cuales se abrieron paso a partir de 1870, con picos y cuellos de terminación industrial (1880 - 1890) (Schávelzon, 1991) (Figura 4). 


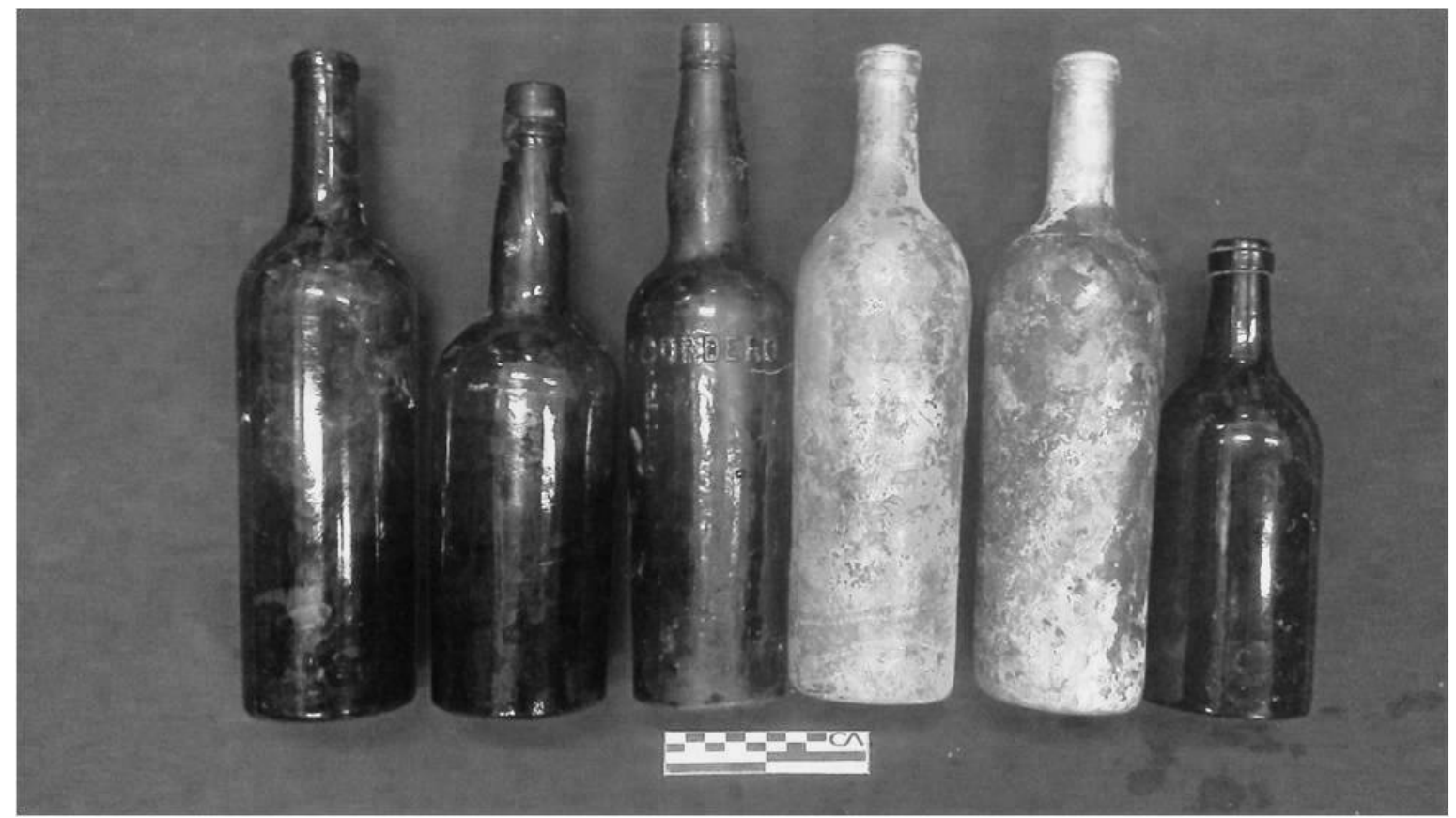

Figura 4: Botellas de vidrio de diferentes tipos de bebida. Fines siglo XX - principios siglo XX

Pueden apreciarse entre las mismas, una de agua mineral marca Krondorf. Estas botellas son cilíndricas, de color verde oscuro (aunque no tanto como las tradicionales de vino producidas en Inglaterra) y con pico redondeado, para poder ser bebidas sin vaso, directo desde la botella. La marca estaba impresa en relieve en la base con la inscripción para nuestro país de Julio Kristufek, su importador y a quien se le hacían las botellas especialmente, abajo decía Buenos Aires ya con "i” latina (pos 1900-10) y en el centro la marca Krondorf, todo en letras de imprenta de igual tamaño (Schávelzon, 2005). También se identificó una botella de vino de Francisco Cordero, muy difundido durante las primeras décadas del Siglo XX.

En cuanto a los restos óseos de animales hallados, la mayor parte de los mismos, se atribuye al descarte de desechos de alimentos (vaca, oveja y gallina). En menor medida, se recuperaron uno pocos huesos correspondientes a gatos y aves paseriformes. El detalle diagnóstico que puede acercarnos a la cronología de su consumo, lo constituyen las marcas de corte con sierra eléctrica, la cual comenzó a difundirse en nuestra ciudad a principios del siglo XX.

\section{Rodamientos de la ingresión belgranense}

Uno de los hallazgos, corresponde a rocas (con signos de rodamiento) propias de la ingresión belgranense, transgresión marina que se produjo hace unos 100.000 años y que fuera descripta por primera vez por Auguste Bravard cuando observara restos de fauna marina en las rocas de las Barrancas de Belgrano (Tonni y Pasqualli, 2004). Las rocas rescatadas en el pozo 1 son muy similares a las rescatadas en las Barrancas de Belgrano, en cuyas inmediaciones existió un yacimiento de conchillas que constituía uno de los epicentros de extracción de estos recursos en la zona. El banco de depósitos calcáreos fue explotado por los padres franciscanos, quienes construyeron un horno con el que comenzaron a fabricar la cal destinada a levantar la Iglesia de San Francisco, en la actual esquina de Alsina y Defensa. Esta producción fue facilitada en gran medida por la autorización de Juan de Espinosa -propietario desde 1726 de estas tierras- quien la otorgó a cambio de 200 pesos plata. Además se permitía a la congregación y a quienes formaran parte del proyecto, a 
que pudieran levantar sus ranchos y corrales en las cercanías, así como disponer de sus bueyes y caballos. (Mayochi, 1992)

La ubicación de la calera de los franciscanos fue materia de debate durante largo tiempo. Hay quienes la situaron en la parte alta de la barranca entre Sucre y Juramento. Otros, como Alfredo Taullard, la ubicaron en las proximidades del arroyo Vega en la calle Blanco Encalada, y Hector Otonello la precisó en la intersección de las calles 3 de Febrero y Mendoza, lo cual parece confirmarse en el plano de Pedro Benoit del 28 de diciembre de 1855 (Archivo del Instituto Histórico del Gobierno de la Ciudad de Buenos Aires). Hacia 1780, los franciscanos abandonan la explotación de cal, aunque hay datos que sostienen que durante la época de Rosas se seguía explotando (Schávelzon y Silveira, 2004)

La presencia de "la Calera", le dio a estas tierras el nombre, lo cual puede apreciarse en los primeros planos de la zona "Pueblo Nuevo de la Calera" (Schávelzon y Silveira, 2004).

\section{Consideraciones finales}

De acuerdo al diagnóstico del material hallado en el pozo $\mathrm{N}^{\circ} 1$ y a la información histórica recabada sobre los edificios que se levantaron en el lote que ocuparan las familias Chas y Larreta, se puede inferir estamos ante una estructura sanitaria asociada a una construcción -que como se aprecia en planos de fines del siglo XIX y principios del XX- se ubicaba con frente sobre la actual calle Cuba, y que de hecho formaba parte integral del lote propiedad de la familia Larreta.

Si bien los niveles estratigráficos excavados alcanzan algo más de 5 metros desde la boca del pozo, los materiales recuperados se asocian a un mismo evento de descarte, caracterizado por la constante presencia de restos de materiales constructivos que formarían parte de algún tipo de reformas emprendidas en la antigua Casa Chas, y que algunas de sus estructuras demolidas, posiblemente aquella que tenía frente sobre la calle Cuba fueran descartadas en este pozo.

La cronología del material puede sostener esta asociación con estas las modificaciones llevadas a cabo en el lote, dado que con el diagnóstico de los restos recuperados, se puede afirmar que la fecha promedio de descarte estaría situada entre las primeras dos décadas del siglo XX. Clavos de cabeza redonda, restos óseos con cortes de sierra eléctrica, son algunos de los marcadores diagnósticos que nos acercan a este segmento temporal vinculado a las reformas encomendadas por Enrique Larreta en 1916.

\section{Referencias}

ALLENDE, A. (1958). Los orígenes del Pueblo de Belgrano 1855 - 1862 La Plata. Dirección de impresiones oficiales.

CASElla DE CALDERÓN, E. (1986) Buenos Aires nos cuenta. $N^{o} 11.1^{\circ}$ Edición. Buenos Aires: CPC Impresores.

CASElla DE CALDERÓN, E. (1988). Buenos Aires nos cuenta. № 6. $3^{\circ}$ Edición. Buenos Aires: CPC Impresores.

MAYOCHI, E. (1992). Belgrano 1855 - 1992 del pueblo al barrio. Buenos Aires: Fundación Banco de Boston.

PRIGNANO, A. (2007). El inodoro y sus conexiones. Buenos Aires: Ed Biblos.

SCHÁVELZON, D. (1991). Arqueología histórica de Buenos Aires La cultura material porteña de los siglos XVIII y XIX. Buenos Aires: Ed. Corregidor 
SCHÁVELZON, D. (2001). Catálogo de cerámicas históricas de Buenos Aires (siglos XVI - XIX). Buenos Aires. Edición del Autor.

SCHÁVELZON, D. y SILVEIRA M. (2004). Plano del potencial arqueológico de Buenos Aires. Barrio de Belgrano. MS.

SCHÁVELZON, D. (2005). Cien botellas: un hallazgo casual en el convento de Santa Catalina de Buenos Aires (excavación de 2001). Informe preparado para el Centro de Arqueología Urbana.

TONNI, E. y PASQUALLI, R. (2004). Los Mamíferos fósiles de Buenos Aires. Córdoba: Universitas.

Recibido: 10/07/2017

Aceptado: 01/09/2017 